\title{
A Dimensão Oferta à Luz do Radar da Inovação: um estudo sobre o desempenho de agências de turismo do Recife-PE no período de 2012 a 2016
}

Jussara Danielle Martins Aires ${ }^{a}$

\begin{abstract}
Resumo
Diagnosticar o grau de inovação empresarial se mostra uma necessidade para a melhoria do desempenho organizacional. No entanto, essa prática ainda é pouco desenvolvida em micro e pequenas empresas de turismo e carece de investigações no campo acadêmico. Assim, este artigo busca analisar o desempenho quanto ao grau de inovação de agências de turismo do Recife com foco na dimensão oferta à luz de uma ferramenta chamada Radar da Inovação (RI). Os dados foram coletados no período de agosto de 2012 a junho de 2016. A pesquisa se caracteriza como exploratória e descritiva, contando com tratamento e análise de dados sob abordagens quantitativa e qualitativa. Considerando a classificação feita por Bachmann e Destefani em 2008, verificou-se que a maioria das empresas investigadas apresentou aumento nos escores, passando da condição de "pouco ou nada inovadoras" para "inovadoras ocasionais ou sistêmicas", tanto com base nos resultados do grau de inovação global quanto nos escores da dimensão oferta. Constatou-se que, apesar dos avanços, ainda persistem barreiras que limitam a capacidade inovadora dessas agências.
\end{abstract}

Palavras-chave: Oferta; Radar da Inovação; Agências de turismo.

\section{Abstract \\ The Supply Dimension in the Light of Innovation Radar: a study about the performance of travel agencies in Recife-PE in the period from 2012 to 2016}

Diagnosing the innovation degree of firms translates into a need for improved organizational performance. However, this practice is still underdeveloped in micro and small firms of the tourism sector and it lacks researches in the academic field. Thus, this article seeks to analyze the performance with regard to the degree of innovation of travel agencies from Recife (PE - Brazil) focusing on Dimension Offer in light of a tool called Diagnostic Innovation Radar (IR). Data were collected from August 2012 to June 2016. The research is characterized as exploratory and descriptive, with processing and analysis of data made under quantitative and qualitative approaches. Considerating the Bachmann and Destefani (2008)'s classification, it was found that most companies investigated showed improvements in scores, moving from a 'little or nothing innovative "to" occasional or systemic innovative ", both based the results of the Global Innovation Degree, as the scores of the Offer dimension. Despite the progress, there are still barriers that limit the innovative capacity of these firms.

Keywords: Offer; Innovation Radar; Tourism Agencies.

a. Doutora em Turismo pela Universidade de Aveiro, Aveiro, Portugal. E-mail: jussaradma@ua.pt 


\section{Resumen}

La Dimensión Oferta a la Luz del Radar de la Innovación: un estudio sobre el desempeño de las agencias de turismo de Recife-PE, en el período 2012-2016

Diagnosticar el grado de innovación empresarial se traduce en una necesidad de mejorar el desempeño organizativo. Sin embargo, esta práctica es todavía poco desarrollada en micro y pequeñas empresas de turismo y necesita investigación en el campo académico. Por lo tanto, este artículo busca analizar el desempeño y el grado de innovación de las agencias de turismo de Recife, enfocando en la dimensión oferta a la luz de una herramienta llamada Radar da Inovação (RI). Los datos fueron recolectados en el periodo de agosto de 2012 hasta junio de 2016. La investigación se caracteriza como exploratoria y descriptiva, con el procesamiento y el análisis de datos realizados bajo abordajes cuantitativos y cualitativos. Teniendo en cuenta la clasificación de Bachmann y Destefani (2008), se verificó que la mayoría de las empresas encuestadas presentó un aumento en las puntuaciones, pasando de la condición de "poco o nada innovadora" a la de "innovadoras ocasionales o sistémicas", tanto basado en los resultados de grado de innovación global, como en las puntuaciones de la dimensión oferta. Se encontró que, a pesar de los avances, todavía existen barreras que limitan la capacidad de innovación de estas empresas.

Palabras clave: Oferta; Radar da Inovação; Agencias de turismo.

\section{INTRODUÇÃo}

O turismo, como um dos principais segmentos econômicos, evidencia tendências de crescimento mesmo numa época de crise global. No Brasil, esse segmento é predominantemente composto por micro e pequenas empresas (97\%) e se destaca pela geração de emprego e renda, inclusive em taxas superiores às oficialmente previstas (Costa \& Hoffmann, 2014).

Para a constante prosperidade econômica da área, a atuação das agências de turismo ${ }^{1}$ é fundamental. Trata-se de um segmento promissor, formado por um contingente de micro e pequenas empresas (MPE), que movimenta mais de $\mathrm{R} \$ 60$ bilhões por ano no país e constitui elo da extensa cadeia produtiva que engloba um emaranhado de empresas - hotéis, companhias aéreas, locadoras de automóveis, transportadoras turísticas, cruzeiros marítimos, empresas organizadoras de congressos e eventos e restaurantes -, representando um total de 52 segmentos da economia (Agência Sebrae de Notícias, 2013).

A competitividade das agências de turismo, não diferente de outros segmentos econômicos, é uma forma de sobrevivência e está condicionada à capacidade de seus gestores de inovar e buscar aprimorar a inovação continuamente (Machado, Dreher \& Gorni, 2009; Salvado, 2009). Conscientes da necessidade de mensurar esse desempenho, Sawhney, Wolcott e Arroniz (2006) criaram o diagnóstico Radar da Inovação (RI), ferramenta posteriormente adaptada para a realidade das MPE por Bachmann e Destefani (2008), que contribuíram para diagnosticar

1. Compreende-se por agência de turismo a pessoa jurídica que exerce a atividade econômica de intermediação remunerada entre fornecedores e consumidores de serviços turísticos ou os fornece diretamente. São considerados serviços de operação de viagens; excursões e passeios turísticos; e organização, contratação e execução de programas, roteiros, itinerários, bem como recepção, transferência e a assistência ao turista. Para melhores informações, consultar Lei no 11.771 , de 17 de setembro de 2008 (Brasil, 2008). 
o grau de inovação em treze dimensões de pequenas empresas no período de agosto de 2012 a junho de 2016. Dentre elas, estão incluídas 12 agências de turismo situadas em Recife, onde a expansão desse segmento é considerada uma das mais expressivas do país.

Assim, este artigo objetiva mostrar o desempenho (quanto ao grau de inovação) apresentado por essas agências de turismo, com foco na dimensão "oferta", que contempla aspectos como: atuação em novos mercados, lançamento de novos produtos, remoção de produtos sem sucesso do mercado, mudanças nas características de serviços por razões ambientais, modificações significativas no design de produtos e adoção de inovações tecnológicas.

Mensurar e avaliar a inovação em distintas dimensões se mostra uma necessidade para a melhoria do desempenho organizacional e, no entanto, ainda são estratégias pouco desenvolvidas em micro e pequenas empresas. Assim, as poucas ferramentas que cumprem esse papel merecem atenção especial (Hjalager, 2010; Carvalho, Silva, Póvoa e Carvalho, 2015).

Ademais, no âmbito das pesquisas desenvolvidas sobre a temática proposta, percebe-se um déficit de trabalhos que abordem efetivamente a mensuração da inovação e seu desempenho no mercado de agências de turismo (Machado et al., 2009). Destarte, o estudo possibilitará a obtenção de dados que contribuirão para maior compreensão da realidade e tendências do referido segmento. Os resultados desta pesquisa poderão, ainda, subsidiar a criação de novas estratégias e políticas de âmbitos público e privado para as agências de viagens.

Desse modo, considerando a validade do $\mathrm{RI}^{2}$ enquanto instrumento capaz de mensurar a capacidade inovadora geral e por dimensões específicas empresariais, este estudo parte da seguinte questão-problema: quanto ao grau de inovação, qual o desempenho apresentado pelas agências de turismo do Recife, especialmente no tocante à dimensão oferta?

A seguir, são apresentadas a contextualização teórica do tema, contemplando as particularidades da inovação no setor de turismo, ferramentas de mensuração da inovação, o Radar da Inovação e a dimensão "oferta"; a metodologia da pesquisa; a análise e a discussão dos resultados, de modo a confrontá-los com a teoria revisada; as conclusões, mostrando as principais contribuições e limitações do estudo e encaminhamentos para pesquisas futuras; os agradecimentos; e finalmente, as referências.

\section{INOVAÇÃO NO SETOR DE TURISMO}

Conforme esclarecem Brandão e Costa (2014), existem distintos conceitos de inovação, que variam em função da abordagem, da área científica e do domínio de aplicação. De modo geral, eles se baseiam na abordagem schumpeteriana, assim como a Organização para a Cooperação e Desenvolvimento Econômico (OCDE), que deu uma contribuição fundamental para a uniformização e a aplicação da definição também ao setor de serviços por meio do Manual de Oslo, no qual a inovação "consiste na implementação de um produto (bem ou serviço) novo ou

2. Tal ferramenta foi aplicada a partir do contexto do Programa Agentes Locais de Inovação (ALI), um programa de abrangência nacional do Serviço Brasileiro de Apoio às Micro e Pequenas Empresas (Sebrae). A aplicação se deu em quatro etapas, conforme será detalhado na metodologia. 
significativamente melhorado, ou um processo, um novo método de marketing ou organizacional nas práticas de negócios, na organização do local de trabalho ou nas relações externas" (Organização para a Cooperação e Desenvolvimento Econômico, 2005, p. 46).

Para Gomezelj (2016), todas essas definições aplicam-se perfeitamente à indústria manufatureira e vêm sendo adaptadas aos setores de turismo e de serviços em geral nas últimas décadas. Contudo, o primeiro é um setor-chave para se avaliar porque as empresas de turismo têm problemas, características e processos específicos em cada atividade (Camisón \& Monfort-Mir, 2012).

Hjalager (2010) observou que o turismo tem características-chaves para desenvolver novas definições e tipologias de inovação. Então, propôs cinco diferentes tipos de inovação na área:

a) Inovações de produto ou serviço (mudanças que podem ser observadas diretamente pelos turistas e outros clientes, com significado "novo", nunca visto ou simplesmente novo para a empresa ou destino; esses produtos e serviços são benéficos para os turistas de tal forma que podem decidir comprar apenas por ser novidade).

b)Inovações de processo (tipicamente iniciativas de backstage destinadas a melhorar a eficiência e a produtividade; investimentos tecnológicos são os principais fatores de tais inovações).

c) Inovações gerenciais (novas formas de organização dos processos de negócios, capacitação do pessoal, compensação do trabalho exemplar com benefícios financeiros ou não financeiros e melhoria da satisfação no local de trabalho; métodos de retenção de empregados são extremamente valiosos no setor de turismo).

d)Inovações de marketing (incluindo novos conceitos desse campo, como programas de fidelização e coprodução de marcas).

e) Inovações institucionais (novas formas de estrutura colaborativa/organizacional, tais como clusters, redes e alianças).

Essencialmente, essas são as dimensões de inovação usadas ou rearranjadas em vários estudos. No entanto, é difícil distinguir claramente as cinco categorias (produto, processo, gestão, marketing e inovações institucionais), uma vez que existe estreita interação entre elas (Gomezelj, 2016).

Peters e Pikkemaat (2006) enfatizam que, no setor de turismo, as inovações incrementais - que englobam modificações e melhorias significativas - são mais relevantes, já que as inovações radicais (mais visíveis) são raras quando comparadas com aquelas. Em concordância com esse raciocínio, Fayet (2010) pondera que as inovações mais bem-sucedidas são baseadas no efeito cumulativo dessas mudanças incrementais ou na combinação criativa de técnicas, ideias ou métodos existentes.

Por sua vez, Pinto e Cruz (2011) afirmam que a criação e a oferta de novos produtos e serviços na cadeia do turismo não são frequentes e geralmente 
derivam da pressão de fornecedores, clientes e até concorrentes. Para esses autores, muitas empresas insistem em manter um comportamento reativo. Adicionalmente, Sundbo, Orfila-Sintes e Sorensen (2007) e Weidenfeld, Williams e Butler (2010) sublinham que as inovações no setor do turismo são fáceis de imitar, porque são altamente visíveis e seu conteúdo tecnológico costuma ser pouco sofisticado, ou seja, não envolvem avanços tecnológicos significativos e raramente podem ser patenteadas.

Hauser, Tellis e Griffin (2006) mostram que a capacidade inovadora está condicionada à capacidade de aprender, gerar e absorver conhecimento. Os autores também indicam a necessidade de diversas articulações para absorver o conhecimento tácito existente no ambiente. Nesse sentido, Brandão e Costa (2014) afirmam que nas MPE de turismo a maior parte dos recursos humanos apresenta baixos níveis de formação ou formação em outras áreas (não relacionadas com o turismo), o que pode conduzir à falta de capacidade de criar e utilizar o conhecimento para o desenvolvimento da inovação.

Em geral, os resultados relacionados à implementação da inovação nas MPE são insatisfatórios, mesmo no Brasil (Machado et al. 2009). Supostamente, parece oportuno apresentar uma justificativa para esse caso, com base numa concepção de Bes e Kotler (2011): para grande parte dos empresários (diretores de empresas), ainda resiste o pensamento de que a inovação deve necessariamente ser algo completamente inédito e que envolva alta tecnologia e altos investimentos.

Bittar, Siqueira, Luz e Chacon (2014) consideram que existem obstáculos que impedem a maioria dos empreendedores brasileiros de assumir compromissos efetivos com a inovação. Eles não têm conhecimento suficiente para incentivá-los a inovar e ainda não consideram a inovação como algo crucial para a empresa. De fato, existem alguns elementos construtivos pró-inovação, ausentes ou deficientes no país, nomeadamente: aversão ao risco, dependência do Estado, pouco ou nenhum investimento em pesquisa e desenvolvimento (P\&D), falta de cultura pró-inovação (mercado protegido, opção de compra de tecnologia etc.) e pouca aproximação ou falta de interlocução mais pragmática entre universidades e empresas (Bittar et al., 2014).

\section{O RADAR DA INOVAÇÃo E SUAS dIMENSÕES}

Mensurar o grau de inovação empresarial não é uma tarefa fácil, já que não existe um consenso acerca do modelo mais apropriado para aplicação (Cavalcanti, Cavalcanti Filho \& Oliveira, 2012). Na concepção de Bautzer (2009), um bom diagnóstico deve, por meio de processo formal estruturado, identificar elementos como flexibilidade, competitividade, grau de vulnerabilidade e capacidade para implementar estratégias novas.

Numa perspectiva favorável à essa necessidade, Sawhney et al. (2006) propuseram uma ferramenta denominada Radar da Inovação, que relaciona as dimensões pelas quais uma empresa pode procurar caminhos para inovar. Essa ferramenta reuniu, inicialmente, quatro dimensões macroestratégicas denominadas de âncoras empresariais, nomeadamente: as ofertas criadas para o mercado consumidor; os clientes atendidos e suas percepções sobre esse processo; os processos empregados, como produtivo, vendas e gestão; e, por fim, os pontos 
em que a estrutura empresarial/comercialização está situada (Sawhney et al., 2006). Essas dimensões contemplam a técnica 3W1H (What?, o que será feito ação, etapas, descrição; Where?, onde será feito - local; Who?, por quem será feito - responsabilidade pela ação; e How?, como será feito - método, processo). No contexto das 12 agências de turismo do Recife investigadas nesta pesquisa, as aplicações da referida técnica e do Radar da Inovação coincidiram. Em cada etapa, planos de ação foram anexados aos relatórios com os diagnósticos empresariais, relativos ao grau de inovação aos seus respectivos diretores.

Sawhney et al. (2006) decidiram adicionar oito dimensões: 1) plataforma; 2) marca; 3) soluções; 4) relacionamento; 5) agregação de valor; 6) organização; 7) cadeia de fornecimento; e 8) rede. Por sua vez, Bachmann e Destefani (2008) acrescentaram às 12 dimensões de Sawhney et al. (2006) o conceito de ambiente propício à inovação ou ambiência inovadora. A relevância dessa contribuição pode ser percebida e justificada, entre outros aspectos, pela influência do aporte de recursos humanos para as empresas, contribuindo sobremaneira para a formação facilitadora do processo de incorporação e implementação da cultura de inovação.

No Quadro 1 são apresentadas as dimensões da inovação propostas por Sawhney et al. (2006) e complementadas por Bachmann e Destefani (2008), bem como uma breve definição de cada uma delas. Um gráfico radar é utilizado para tornar a apresentação de fácil compreensão e destacar os resultados mais significativos ao serem comparados valores agregados de várias dimensões.

Quadro 1 - Definição das dimensões do Radar da Inovação

\begin{tabular}{|c|c|}
\hline Dimensão & Definição \\
\hline Oferta & Desenvolvimento de produtos com características inovadoras \\
\hline Processos & $\begin{array}{l}\text { Redesenho de processos produtivos de modo a permitir incremento de } \\
\text { eficiência operacional }\end{array}$ \\
\hline Clientes & Identificação de necessidades dos clientes ou novos nichos de mercado \\
\hline Praça & Identificação de novas formas de comercialização e/ou distribuição \\
\hline Plataforma & $\begin{array}{l}\text { Relacionamento com a adaptabilidade do sistema de produção face à } \\
\text { diversidade de produtos demandados }\end{array}$ \\
\hline Marca & Modo como as empresas transmitem aos clientes os seus valores \\
\hline Soluções & Sistemas ou mecanismos para facilitar as dificuldades dos clientes \\
\hline Relacionamento & Relacionamento com experiência do cliente com a empresa \\
\hline Agregação de Valor & $\begin{array}{l}\text { Melhorias no modo de captar o valor dos produtos percebido por } \\
\text { cliente e fornecedores }\end{array}$ \\
\hline Organização & Melhorias da estrutura da empresa \\
\hline $\begin{array}{l}\text { Cadeia de } \\
\text { fornecimento }\end{array}$ & $\begin{array}{l}\text { Incremento da logística com fornecedores e clientes, internos ou } \\
\text { externos }\end{array}$ \\
\hline Rede & Comunicação entre os elos da cadeia de fornecimento \\
\hline $\begin{array}{l}\text { Ambiência } \\
\text { inovadora }\end{array}$ & $\begin{array}{l}\text { Relacionamento com os profissionais que compõem a empresa e que } \\
\text { colaboram com a cultura da inovação }\end{array}$ \\
\hline \multicolumn{2}{|c|}{ Fonte - Sawhney et al. (2006) e Bachmann e Destefani (2008) } \\
\hline
\end{tabular}

De acordo com Ketokivi e Ali-Yrkkö (2010), ações de inovação têm impactos em múltiplas dimensões do radar, mas de maneira diferente para cada empresa. Independentemente da origem da inovação - seja no lançamento de um novo 
produto, uma estratégia de venda ou outra providência -, haverá impacto nas demais dimensões. Esses autores consideram o RI como medida de maturidade do processo empresarial de inovação, especialmente em MPE, com base nos processos específicos dessas empresas, nos resultados e na importância dada ao conhecimento como ferramenta primordial à inovação e que, por conseguinte, visa à competitividade.

Oliveira, Cavalcanti e Paiva Junior (2013, p. 15) apontam uma desvantagem da ferramenta: "o radar de inovação, sobretudo o grau de inovação, tem um problema que é não abordar as empresas levando em consideração a heterogeneidade dos setores a que elas pertencem". Os autores sinalizam os cuidados e a atenção que se devem ter na tentativa de adaptar as questões do radar para os setores de indústria, comércio e serviços. Em consonância, Ketokivi e Ali-Yrkkö (2010) completam que o impacto e a influência que as ações de inovação de uma determinada dimensão do radar exercem sobre outras variam de setor para setor.

Conforme ponderam Bachmann e Destefani (2008), a determinação do RI é um método estruturado que pode oferecer as seguintes vantagens: mensuração quantitativa, pequena subjetividade, referências para melhorias e possibilidade de avaliações setoriais, regionais e históricas. Trata-se da avaliação do grau de inovação cuja determinação se sustenta em três pilares: 1) o que avaliar (dimensões da inovação); 2) como medir (escala usada); e 3) que período de tempo considerar.

Particularmente, em relação à subjetividade, destaca-se que a aplicação do RI está condicionada à concepção, apreciação e interpretação do entrevistado. Relativamente à mensuração quantitativa, conforme será mostrado adiante nos resultados, uma fragilidade é apontada e pode servir até mesmo como potencial contributo para a elaboração de instrumentos mais eficazes de medição: a escala usada no RI é passível de esclarecimentos. A cada grau de 1 a 5 , deveria ser atribuída uma classificação. No entanto, apenas os escores 1, 3 e 5 são contemplados desse modo.

Por outro lado, é evidente que a aplicação desse instrumento permite análise e demonstração das inovações realizadas pela empresa nos últimos três anos, ao mesmo tempo em que explicita sua capacidade de ser (ou não) competitiva. Pode ser utilizado em momentos distintos conforme a necessidade da empresa. 0 grau de inovação global (GIG) evolui (ou não) em função do comportamento dos escores de cada uma das treze dimensões (Bachmann \& Destefani, 2008).

Para Carvalho et al., (2015), o RI pode efetivamente ser utilizado como ferramenta que proporciona vantagens para as empresas, uma vez que lhes permite visualizar como estão se posicionando na condução do negócio e identificar onde se encontram seus impedimentos de melhorias (dimensões pouco exploradas), estabelecendo, por conseguinte, ações que favoreçam a melhoria de seu desempenho e de sua capacidade competitiva.

\section{METODOLOGIA}

Este estudo consiste numa pesquisa exploratória e descritiva. A análise de dados contemplou as abordagens quantitativa e qualitativa. 0 estudo foi teórico-empírico, utilizando dados primários, obtidos por meio de questionários 
aplicados presencialmente com os diretores das referidas agências ${ }^{3}$ no período de agosto de 2012 a junho de 2016 . Além disso, foram utilizados recortes de falas de empresários (gravadas com a devida autorização destes) para complementar os dados quantitativos. Os dados empíricos foram confrontados com as principais teorias discutidas.

O Sebrae, em parceria com o Conselho Nacional de Desenvolvimento Científico e Tecnológico (CNPq), desenvolveu o Programa Agentes Locais de Inovação (ALI), ${ }^{4}$ de abrangência nacional, com o objetivo de fomentar a prática da inovação em micro e pequenas empresas e sensibilizar os empresários acerca da importância da inovação como fator de competitividade (Sebrae-PR, 2017). Para Carvalho et al., (2015) a sensibilização e o estímulo à prática da inovação por meio de iniciativas como essas têm sido vistos como exitosos e favoráveis também aos empresários, por potencializar ganhos às empresas pelo aumento da qualidade e da produtividade de seus serviços aos clientes.

0 acompanhamento feito às MPE contemplou as seguintes etapas: antes de tudo, julgou-se necessário investigar se as empresas dispunham de ferramentas para seu planejamento e se possuíam uma estrutura adequada com o mínimo necessário para adotar e manter as ações de inovação que viessem a ser sugeridas. Assim, após a adesão, um diagnóstico inicial da empresa foi feito por meio do RI (etapa $\mathrm{R}_{0}$ ) e os empresários responderam a um inquérito, no qual era necessário evidenciar as respostas. Depois, um relatório chamado de devolutiva, contendo um plano de ações com sugestões de ações inovadoras (a ser implementado sob a responsabilidade do empresário) e a indicação de possíveis provedores de soluções, foi entregue ao empresário.

Em um segundo momento, um novo ciclo de diagnóstico (etapa $\mathrm{R}_{1}$ ) foi realizado para constatar a ocorrência de evolução (ou não) da empresa e, assim, novas ações foram propostas. 0 final de um ciclo se dava quando pelo menos três ações eram implementadas. Isso aconteceu de tal sorte que o momento para entregar a devolutiva final (etapa $R_{3}$ ) revelou a evolução (ou não) do desempenho da empresa em relação ao grau de inovação e aos principais resultados alcançados. É importante salientar que a aplicação do RI levou em conta as mesmas questões ao longo das etapas mencionadas.

Embora o programa tenha alcançado um número maior de agências de turismo e mesmo de pequenas empresas de outros setores econômicos no Brasil e no estado de Pernambuco, a escolha das 12 (doze) agências de turismo desta investigação (todas cadastradas em Recife) se deveu ao fato de essas terem sido as únicas a receber os pesquisadores. Assim, pode-se dizer que foi utilizada uma amostragem não probabilística, por acesso, que, conforme asseverou Mattar (2005), é aquela em que a seleção dos elementos da população para compor a amostra depende ao menos em parte do julgamento do pesquisador ou do

3. Buscou-se, durante a execução de todas as etapas, contatar presencialmente os entrevistados, cada qual desempenhando o cargo de diretor(a) ou representante legal de sua respectiva empresa. Também vale acrescentar que, além do contato presencial, a comunicação com alguns empresários se deu por e-mail e telefone.

4. As empresas investigadas nesta pesquisa foram captadas a partir do contexto da segunda edição do Programa ALI no estado de Pernambuco. Os agentes locais de inovação (bolsistas do CNPq) que acompanharam as empresas participantes receberam previamente treinamento e capacitação sobre inovação por parte do Sebrae. Inclusive, pesquisadores e consultores seniores daquela instituição orientaram o trabalho dos agentes no decorrer do programa. 
entrevistador no campo. Assim, validaram-se os dados coletados em doze MPE do setor de agenciamento de turismo.

A coleta dos dados foi realizada por meio da aplicação do RI com o intuito de mensurar o grau de inovação das empresas gerado pelo Radar nas 13 dimensões apresentadas, por meio de questões objetivas (múltipla escolha) direcionadas especificamente aos proprietários e sócios das empresas, nas quais as respostas para cada uma possuíam escores que permitiram o cálculo do GIG, que é o escore que revela o resultado ou nível de inovação geral da empresa.

0 processo de medição do grau de inovação nas empresas foi baseado na classificação de Bachmann \& Destefani (2008), na qual são utilizadas apenas três situações, embora a ferramenta RI possua uma graduação ampliada de 1 a 5, sendo: (1) organização pouco ou nada inovadora; (3) organização inovadora ocasional; e (5) organização inovadora sistêmica. Estabeleceu-se que se o escore obtido pela empresa (seja por dimensão específica ou global) variasse entre 1,0 e 3,0 significaria que ela é uma organização pouco ou nada inovadora; ao passo que se a variação fosse entre 3,0 e 5,0, indicaria que a empresa inova ocasional ou sistematicamente (Bachmann \& Destefani, 2008).

Um olhar crítico para essa ferramenta permite identificar uma lacuna, que desde já pode servir como contributo ou sugestão para criação ou aprimoramento de instrumentos que possuam a finalidade de medição da inovação empresarial. Particularmente, o RI torna a classificação incompleta e, de certa forma, confusa, pelo fato de não atribuir situações para as graduações 2 e 4, o que pode acabar por desconsiderar a influência no grau de inovação de algumas ações implementadas pelas empresas.

Os dados coletados junto às empresas foram analisados e processados por meio de planilha do Excel. Relatórios foram elaborados e entregues aos empresários participantes da pesquisa, de modo a mostrar o desempenho gerencial, a evolução (mediante gráficos e tabelas) e as justificativas do grau de inovação global e por dimensão em suas empresas ao longo das etapas (nomeadas, neste estudo, de $R_{0}, R_{1}, R_{2}$ e $R_{3}$ ). Levou-se em conta recomendações de Bautzer (2009), segundo as quais um bom diagnóstico deve, por meio de um processo formal estruturado, identificar elementos como flexibilidade, competitividade, grau de vulnerabilidade e capacidade para implementar estratégias novas.

Embora os esforços tenham permitido captar resultados das treze dimensões, a ênfase dada à dimensão oferta dentre as demais deveu-se à percepção e à necessidade de revelar que a maior parte das ações implementadas pelas empresas investigadas contemplavam aspectos como atuação em novos mercados, lançamento de novos produtos, remoção de produtos sem sucesso do mercado, mudanças nas características de serviços por razões ambientais, modificações significativas no design de produtos e adoção de inovações tecnológicas que abordam a referida dimensão.

\section{RESULTADOS}

\section{Perfil das empresas e seus diretores}

Quanto ao gênero, identificou-se a expressiva predominância masculina na gestão dos empreendimentos em questão, percentual equivalente a $75 \%$ da amostra. 
Em muitos casos, as agências de turismo, sendo do tipo familiar, são representadas legalmente pelos provedores da família (que incluem tanto homens como mulheres), mas também são gerenciadas por cônjuges e/ou filhos, que muitas das vezes são sócios. No entanto, para efeitos de esclarecimentos, o percentual apresentado contempla apenas os representantes legais. Tal informação encontrou respaldo na consulta dos contratos sociais de cada uma dessas empresas e dos dados do Cadastro de Prestadores de Serviços Turísticos (Cadastur).

Metade dos diretores entrevistados declarou ter concluído, pelo menos, um curso de graduação (em Administração ou Turismo), seguidos dos pós-graduados (25\%) e dos que apenas concluíram o Ensino Médio (17\%). Apenas um gestor lamentou não ter concluído o Ensino Superior (8\%). Julgou-se necessário investigar se as empresas dispunham de ferramentas para o seu planejamento e se possuíam uma estrutura adequada com o mínimo necessário para adotar e manter as ações de inovação. Assim, antes da aplicação do $\mathrm{R}_{0}$ (etapa inicial), os empresários responderam a um inquérito. Em todos os casos, o discurso dos entrevistados e as evidências observados in loco apontaram que tais diretores agiam intuitivamente, apenas com base na própria experiência cotidiana.

Em relação à faixa etária, foi identificada a predominância de adultos entre 30 e 49 anos entre os entrevistados (50\%). Adultos entre 50 e 60 anos equivalem a $33 \%$ da amostra e os demais (17\%) possuem entre 20 e 29 anos. Curiosamente, percebeu-se uma forte resistência, principalmente por parte do público entre 50 e 60 anos, quanto à adesão ao programa. Com efeito, os momentos de sensibilização e acompanhamento foram oportunos, principalmente por desmitificar o conceito de inovação, presente na percepção desses empresários, conforme previsto por Bes e Kotler (2011). A desmitificação dessas ideias levou em conta a concepção de Bautzer (2009).

A partir da consciência de que a capacidade de inovar deve ser comum e é condição sine qua non de (sem a qual não existe) competitividade e sobrevivência para todas as empresas (Machado et al. 2009; Salvado, 2009), independentemente de tamanho e tempo de permanência delas no mercado, desvela-se que, quanto ao porte, apenas $25 \%$ dos empreendimentos em questão declararam-se como pequenos, sendo a maior parte (75\%) composta por microempresas. Buscou-se confirmar essas informações pela observação/constatação do número mínimo e máximo de funcionários sob o regime de carteira assinada em todas as agências (variou entre 2 e 5 funcionários). Além disso, realizou-se consulta da situação de cada uma das empresas pelo seu Cadastro Nacional de Pessoa Jurídica (CNPJ). Já o quesito "tempo de permanência no mercado" dividiu-se em três grupos: entre 1 e 5 anos (50\%), entre 6 e 9 anos (25\%) e 10 ou mais anos (25\%). Os dados mostraram que nem sempre as empresas de pequeno porte estão mais propensas ou são mais inovadoras do que as micro. A mesma observação se aplica ao tempo de permanência no mercado: houve casos em que empresas com menos tempo de atuação obtiveram maiores escores no GIG ao longo das etapas do que outras mais antigas.

Relativamente às funções operacionais das agências de turismo, é mister salientar, que em conformidade com a Lei no 12.974 , de 15 de maio de 2014 (Brasil, 2014), duas categorias foram identificadas dentre as 12 empresas investigadas: duas agências de viagens e turismo (AVT), também denominadas de operadoras turísticas, desempenhando funções como assessoramento, planejamento e organização de atividades associadas à execução de viagens turísticas e 
excursões ou de programas, serviços, roteiros e itinerários de viagens individuais ou em grupo; e dez agências de viagens (AV) que exerciam como atividade principal a venda comissionada ou a intermediação remunerada na comercialização de passagens, passeios, viagens e excursões, nas modalidades aérea, aquaviária, terrestre, ferroviária ou conjugada.

Embora a atuação em emissivo e receptivo ocorra simultaneamente em todas as agências de viagens, em quatro delas é dada atenção especial aos serviços de receptivo, de forma a explorar roteiros locais (passeios/roteiros de praias do litoral Sul do estado de Pernambuco foram citados como produtos de maior procura nesses casos). Também foi constatado que todas as 12 agências de turismo possuíam o Cadastur em vigor e afiliações à Associação Brasileira das Agências de Viagens (Abav), ao Sindicato das Empresas de Turismo do Estado de Pernambuco (Sindetur/PE) e ou à Associação Internacional de Transporte Aéreo (Aita; em inglês, International Air Transport Association - Iata).

\section{O grau de inovação global das agências de turismo}

Conforme dito, o diagnóstico $\mathrm{RI}$ foi aplicado quatro vezes (etapas $\mathrm{R}_{0}, \mathrm{R}_{1}, \mathrm{R}_{2}$ e $\mathrm{R}_{3}$ ) em todas as agências participantes do programa. Escores foram gerados para cada uma das 13 dimensões do diagnóstico, fornecendo o resultado do GIG, conforme ilustra a Tabela 1.

Tabela 1 - Grau de inovação global (GIG) das agências de turismo

\begin{tabular}{|c|c|c|c|c|}
\hline \multirow{2}{*}{ Empresas } & \multicolumn{5}{|c|}{ Grau de Inovaça Global (GIG) } & \\
\hline & GIG (R0) & GIG (R1) & GIG (R2) & GIG (R3) \\
\hline A & 2,9 & 3,2 & 3,8 & 4,3 \\
\hline B & 2,5 & 2,8 & 3,5 & 3,8 \\
\hline C & 3,4 & 3,8 & 4,3 & 4,5 \\
\hline D & 3,4 & 3,6 & 3,9 & 4,2 \\
\hline E & 2,5 & 2,9 & 3,6 & 4,3 \\
\hline F & 2,8 & 3,4 & 3,9 & 4,2 \\
\hline G & 3,0 & 3,4 & 4,0 & 4,6 \\
\hline I & 2,8 & 3,6 & 4,2 & 4,8 \\
\hline J & 2,7 & 3,1 & 3,9 & 4,1 \\
\hline K & 2,3 & 2,6 & 3,2 & 3,6 \\
\hline L & 2,9 & 3,2 & 3,6 & 3,8 \\
\hline
\end{tabular}

A partir desses resultados, é possível afirmar que houve aumento do GIG em todas as empresas analisadas. Avanços que foram unânimes tanto da etapa $R_{0}$ para a $R_{1}$ quanto da $R_{1}$ para a $R_{2}$ e da $R_{2}$ para a $R_{3}$ e evidenciam o cumprimento, por parte dos empresários, de ações de melhoria. Vale esclarecer que nesta pesquisa foram seguidas as mesmas etapas descritas no referencial teórico e na bibliografia, embora que tenha sido constatada (desde o momento da aplicação) 
a necessidade de se fazer algumas adaptações nas questões do inquérito (RI) para o devido enquadramento no contexto das empresas investigadas. Tal observação confirma o previsto por Oliveira et al. (2013): o RI não aborda as empresas levando em consideração a heterogeneidade dos setores aos quais elas pertencem. Nesse caso, percebeu-se que as questões contemplavam mais adequadamente o setor de indústria.

Verificou-se ainda que em todas as agências de turismo a quantidade de implementações de ações inovadoras incrementais, sobretudo no que tange às melhorias de produtos ou serviços, por meio da criação de novas versões deles, foi bastante expressiva, conforme será apresentado adiante. Essa constatação corrobora a concepção de Peters e Pikkemaat (2006) de que no setor de serviços turísticos, inclusive em agências de turismo, esse tipo de inovação ocorre com muito mais frequência e tem relevância acrescida.

Levando-se em consideração a classificação de Bachmann e Destefani (2008), pode-se dizer que a maioria das empresas foi diagnosticada com escore de pouco ou nada inovadoras e chegaram à etapa $\mathrm{R}_{3}$ alcançando um patamar que as qualificou como inovadoras ocasionais ou sistêmicas, embora fosse identificada uma lacuna relativa à escala e à classificação dos escores (apenas 1, 2 e 3) usada no RI. Assim, um dos contributos desta pesquisa é sugerir que para cada grau de 1 a 5 fosse atribuída uma situação e, dessa forma, além de enriquecer a classificação (tornando-a menos confusa), reduzir ou eliminar a probabilidade de invalidar o impacto de algumas ações de inovação.

A estratégia de fornecer ao empresário, por meio do RI, uma análise da situação empresarial, identificando elementos como flexibilidade, competitividade, grau de vulnerabilidade e capacidade de implementar ações inovadoras, é pertinente, bem-sucedida e eficaz, de acordo com a perspectiva de Bautzer (2009). Sua importância foi explicitada ainda no depoimento de um dos empresários: "Diagnosticar a empresa e as forças que interferem no funcionamento dela foram fundamentais para definir as ações mais importantes a serem desenvolvidas". ${ }^{5}$

Esse depoimento contempla ainda a suposição de Carvalho et al. (2015), segundo a qual a sensibilização e o diagnóstico do grau de inovação constituem uma iniciativa favorável e exitosa para os empresários.

Durante a realização dos diagnósticos, observou-se a preocupação dos entrevistados em investir em práticas de inovação sustentáveis expressas, sobretudo, em melhorias graduais em produtos ou serviços, organização, marketing ou, ainda, processos das empresas, o que contempla parcialmente a tipologia da inovação das empresas de turismo apresentada por Hjalager (2010). Inovações de produto ou serviço (mudanças que podem ser observadas diretamente pelos turistas e outros clientes, com "novo" significado, nunca visto ou simplesmente novo para a empresa); de processo, destinadas a melhorar a eficiência e a produtividade; e de marketing (incluindo novos conceitos de marketing, como programas de fidelização e coprodução de marcas) foram os tipos mais comumente observados no contexto das empresas analisadas.

5. Entrevista concedisa por A. S. Lins em 9 de janeiro de 2014. 


\section{Escores obtidos na dimensão oferta}

Os escores relacionados à dimensão oferta, bem como ao GIG, mostraram aumentos significativos ao longo das etapas $R_{0}, R_{1}, R_{2}$ e $R_{3}$ e. A Tabela 2 mostra a evolução dos escores na referida dimensão.

Tabela 2 - Evolução dos escores obtidos na dimensão oferta

\begin{tabular}{|c|c|c|c|c|}
\hline \multirow{2}{*}{ Empresas } & \multicolumn{4}{|c|}{ Comparativo dos escores obtidos na Dimensão Oferta } \\
\hline & Oferta (R0) & Oferta (R1) & Oferta (R2) & Oferta (R3) \\
\hline A & $\mathbf{2 , 0}$ & $\mathbf{2 , 5}$ & $\mathbf{3 , 5}$ & $\mathbf{3 , 8}$ \\
\hline B & 1,0 & 1,5 & 2,0 & 2,5 \\
\hline C & 1,5 & 2,5 & 3,0 & 3,5 \\
\hline D & 3,5 & 3,5 & 4,0 & 4,0 \\
\hline E & 1,0 & 2,5 & 3,0 & 3,5 \\
\hline F & 2,0 & 2,5 & 3,5 & 3,5 \\
\hline G & 3,5 & 4,0 & 4,0 & 4,5 \\
\hline H & 1,0 & 2,0 & 2,5 & 3,5 \\
\hline I & 2,0 & 2,5 & 3,5 & 3,5 \\
\hline J & 1,5 & 2,0 & 2,5 & 3,0 \\
\hline K & 2,0 & 2,0 & 2,5 & 3,5 \\
\hline L & 2,0 & Fonte - Elaboração própria & & 4,0 \\
\hline
\end{tabular}

Conforme mostrado na Tabela 2, nenhuma das empresas analisadas chegou à etapa $\mathrm{R}_{3}$ com o mesmo escore obtido na fase inicial. Em $92 \%$ das empresas investigadas, o aumento do desempenho nessa dimensão ocorreu tanto da etapa $R_{0}$ para a $R_{1}$ quanto da $R_{1}$ para a $R_{2}$ Já da etapa $R_{2}$ para a $R_{3}$, somente quatro empresas (33\%) mantiveram seus escores, mesmo tendo evoluído para uma melhor condição em relação à etapa inicial. Os dados mostram ainda que, em função do RI, as melhorias nos escores das empresas foram pouco significativas em apenas três delas (25\%), uma vez que na referida dimensão elas permaneceram na condição de pouco ou nada inovadoras, embora tenham implementado ações significativas. As demais se tornaram inovadoras ocasionais ou sistêmicas, com base na classificação de Bachmann e Destefani (2008). Muitas ações inovadoras incrementais, além de contribuir para aumentar os escores da dimensão oferta, impactaram positivamente outras dimensões do radar, tal como observaram Ketokivi e Ali-Yrkkö (2010). De fato, esses resultados têm mostrado que há uma estreita relação entre as dimensões das ações inovadoras (Gomezelj, 2016).

\section{Variáveis da dimensão oferta e ações implementadas}

A apresentação dos resultados das variáveis que compõem a dimensão "oferta" dividiu-se da seguinte forma: 1) novos produtos; 2) ousadia; 3) resposta ao meio ambiente; 4) design; e 5) inovações tecnológicas. Na etapa $\mathrm{R}_{0}$, as questões do RI investigavam as mudanças feitas na empresa, considerando os últimos três 
anos a partir da aplicação do diagnóstico. Ao longo das etapas, esse intervalo de tempo ia diminuindo, conforme a situação de cada uma delas. Com base no conceito de que uma empresa inovadora tem parte relevante de sua receita associada à criação de novos produtos ou serviços, a avaliação do grau de inovação incluiu a questão: "a empresa lançou, com sucesso, algum novo produto ou serviço no mercado nos últimos meses?". A grande maioria (mais de $80 \%$ ) afirmou ter lançado novos serviços nos intervalos de $R_{0}$ para $R_{1}$, de $R_{1}$ para $R_{2}$ e de $R_{2}$ para $R_{3}$.

Outro fator de influência observado nesse item está relacionado às mudanças de concepção dos empresários a respeito da inovação e de sua importância. A fala de um empresário cuja empresa obteve escore inicial 2,0, alcançando 2,5 na etapa seguinte e 4,0 nas fases R2 e R3, reforça essa influência, ao passo que justifica o progresso: "Aí, de 2012 pra cá, veja que foram mais de cinco serviços criados: teve a remessa expressa, entregas em domicílio, cartão VTM, cartão de crédito com a bandeira da empresa e oferta de pacotes personalizados, explorando novos destinos". ${ }^{\circ}$

A remessa expressa e o cartão Visa Travel Money (VTM) foram novidades mencionadas também por outros empresários. Trata-se de um produto com o objetivo de enviar recursos (dinheiro) do Brasil para o exterior, mediante confirmação de pagamento do cliente. Por sua vez, o cartão VTM é um cartão pré-pago internacional, recarregável em moeda estrangeira, que permite ao cliente efetuar compras na rede Visa e saques em caixas automáticos de bandeira Visa Plus, sempre na moeda local do destino escolhido pelo consumidor. A fala a seguir mostra o impacto dessa inovação para a empresa G.: "Sim, a criação do cartão VTM e a remessa expressa foram produtos que tiveram muito sucesso [...] eles contribuíram para aumentar nosso faturamento em mais de 20\% no ano passado em relação a 2012".

Vale salientar que muitas dessas implementações, a exemplo do cartão VTM, não se traduzem como serviço ou produto criado pela empresa, embora possam ser novas para ela e para os consumidores e comum para o mercado em que atua. Conforme previsto por Hjalager (2010), inovações de produto ou serviços como essas já mencionadas podem ser observadas diretamente pelos clientes, com "novo" significado, nunca visto ou simplesmente novo para a empresa. São assim, benéficas para os turistas, de tal forma que podem decidir comprar apenas por ser novidade (Hjalager, 2010).

O carácter imitativo e pouco sofisticado facilita a replicação das ações tidas como inovadoras no setor turístico e mais especificamente no mercado em questão (Sundbo et al., 2007; Weidenfeld et al., 2010). A partir da aplicação dos diagnósticos, das entrevistas e das observações durante o acompanhamento do desempenho das empresas, também se verificou que estas assumiram um comportamento reativo, ofertando serviços mediante a pressão de clientes e fornecedores, conforme foi asseverado por Pinto e Cruz (2011).

Apesar dos aumentos nos escores e com base em Hauser et al. (2006), pode-se afirmar que a capacidade inovadora da maioria das empresas investigadas foi parcialmente comprometida, já que os empresários declararam e demonstraram agir de forma intuitiva, apenas com base na experiência. Vale lembrar a forte influência que a capacidade de aprender, gerar e absorver conhecimentos exerce sobre a capacidade de inovar. Articulações diversas para absorver os

6. Entrevista concedida por A. S. Lins em 9 de janeiro de 2014.

7. Entrevista concedida por P. T. Gomes em 22 de janeiro de 2014. 
conhecimentos tácitos existentes nas empresas também são indispensáveis (Hauser et al., 2006). No entanto, essas necessidades são práticas incipientes ou não existentes nas agências analisadas. A falta de colaboradores qualificados e treinados internamente (prevista por Brandão \& Costa, 2014) e a ausência de parcerias interempresariais e entre organizações e universidades (prevista por Bittar et. al., 2014) foram algumas das mais frequentes queixas apresentadas pela maioria dos empresários. As inovações institucionais (novas formas de estrutura colaborativa/organizacional, como clusters, redes e alianças) e as gerenciais, destacadas como um dos principais tipos de inovação característica das empresas de turismo, não foram nesse caso tão expressivas quanto as inovações de produto e de marketing, segundo a tipologia de Hjalager (2010).

Quanto ao quesito ousadia, ou seja, a disposição para correr riscos, a avaliação por meio do radar incluiu a seguinte questão: "a empresa, nos últimos meses, retirou do mercado algum produto ou serviço, que não teve sucesso?" A resposta do empresário C. contempla a realidade de mais outros quatro empresários: "Sim, tivemos que retirar o serviço de entrega em domicílio, porque era uma coisa que trazia muitos desgastes e custos desnecessários para gente [...] tivemos a má sorte de encontrar motoqueiros desonestos e em muitos casos, o nosso cliente ficava aborrecido. Nós estamos sempre prontos para agradar o cliente".8

A criação de novos serviços está tão suscetível ao fracasso quanto ao sucesso, mas o fundamental é que o empresário tenha a sensibilidade de perceber e retirar do mercado produtos ou serviços que não agradam a seus clientes nem atendam a suas necessidades e expectativas. Isso está de acordo com a concepção de Pinto e Cruz (2011), segundo a qual clientes exercem fortes influências sobre as inovações de produto e serviço.

Com a rápida evolução das mudanças comportamentais do consumidor, que está cada vez mais exigente, principalmente no quesito sustentabilidade, o questionário do RI também incluiu a pergunta: "a empresa modificou, nos últimos anos ou meses, alguma característica de seus produtos ou serviços por razões ambientais (ecológicas)?". Apenas três empresários afirmaram tê-lo feito, citando como exemplos a adoção de estratégias como a utilização de recicláveis para a confecção de materiais de divulgação e fabricação de brindes com a logomarca das empresas, a digitalização de documentos, a adoção do marketing digital e o selo de apoio à sustentabilidade.

0 quarto e último item da dimensão se refere às inovações tecnológicas que as empresas adotaram de 2012 a 2016. Tendo em vista que a comunicação se faz cada vez mais necessária para atingir o público-alvo, dentro dela encontra-se o design - não só da embalagem, mas também do produto em si. Para avaliar esse quesito, partiu-se da seguinte questão: "ocorreram mudanças significativas na estética, desenho ou de ordem subjetiva em mais de um produto ou serviço?". Foi mais expressiva a quantidade de empresas que realizaram transformações significativas de ordem subjetiva em seus produtos ou serviços, na estética e no desenho. Dentre os exemplos, foram mencionados redesign ou (re)criação e registro de marca, personalização e distribuição de brindes aos clientes com a logomarca da empresa, (re)decoração de ambiente, reformas infraestruturais, ampliação do

8. Entrevista concedida por R. L. Canejo em 20 de fevereiro de 2014. 
espaço físico - com a aquisição de novas sedes -, abertura de filiais, equipamentos e recursos para melhor atender aos clientes.

No relato apresentado a seguir, são mencionados outros exemplos de ações inovadoras de ordem subjetiva e de estética feitas em uma das agências analisadas: " $O$ telão, ilustrando fotos de viagens e depoimentos de nossos clientes foi um estratégia bem-sucedida [...] eles acharam melhor o novo design da logomarca, que inclusive, a gente fez questão de mostrar no site, cartões de visita e nos documentos em papel timbrado da empresa". ${ }^{9}$ Essas ações também consolidam e contemplam a inovação de marketing como sendo frequente e característica nas empresas turísticas, a exemplo das agências de turismo, em conformidade com o suposto por Hjalager (2010).

O caráter imitativo das inovações, a pouca sofisticação de seu conteúdo (pouco envolvimento das empresas com tecnologias mais avançadas) e o desinteresse pelo registro de marcas e patentes foram percebidos em quase todas as empresas (apenas uma delas mobilizou esforços para registrar sua marca). Todas essas percepções contemplam as considerações antecipadas por Sundbo et al. (2007) e Weidenfeld et al. (2010).

Nenhuma das empresas investigadas declarou investir em P\&D, mesmo sendo esta uma prática mais comum em empresas de base tecnológica, como ponderou Ketokivi e Ali-Yrkkö (2010). Obstáculos que impedem avanços maiores relativos à inovação, apontados por Bittar et al. (2014), mostraram estar em conformidade com os resultados apresentados. Investimentos tecnológicos tipicamente representados por iniciativas de backstage destinadas a melhorar a eficiência e a produtividade (inovações de processo, de acordo com a tipologia de Hjalager, 2010), também não se aplicaram frequente e comumente no contexto das empresas estudadas.

\section{CONCLUSões}

Este artigo cumpriu o propósito de avaliar o grau de inovação, com foco na dimensão "oferta", à luz do RI em 12 agências de viagens do Recife. Revisou-se a literatura trazendo à tona concepções relevantes e diálogos entre alguns dos principais autores que abordam o fenômeno da inovação no contexto empresarial e no turismo. Posteriormente, essas discussões foram confrontadas com os dados empíricos.

Uma vez conscientes do diagnóstico de suas empresas, por meio do RI, os empresários entrevistados implementaram inovações ou desenvolveram estratégias que culminaram com a melhora significativa dos resultados inicialmente apresentados, apesar de em alguns poucos casos o aumento nos escores não ter permitido alcançar maior patamar na classificação de Bachmann e Destefani (2008). Com base nesta, pode-se dizer que a maioria das empresas apresentou escores iniciais que as categorizaram como pouco ou nada inovadoras e chegaram à etapa $\mathrm{R}_{3}$ alcançando uma condição que as qualificou como inovadoras ocasionais ou sistêmicas, tanto com base nos resultados do GIG quanto nos escores da dimensão "oferta".

A partir dos resultados e em consonância com discussões teóricas, pode-se concluir que, apesar de os esforços terem provocado contributos significativos

9. Entrevista concedida por F. M. Ishoa em 24 de janeiro de 2014. 
nessas empresas, ainda persistem barreiras (relativas à gestão do conhecimento interno e externo, formação de redes e parcerias interorganizacionais e investimentos tecnológicos, para citar alguns exemplos) que limitam a sua capacidade inovadora. Com efeito, a pesquisa reforçou a concepção de que a evolução da capacidade de inovar também está condicionada a forças externas às empresas, de tal sorte que, por mais bem-sucedidos e exitosos que sejam os esforços para efetivar a inovação dentro delas, se estes ocorrem de forma isolada, acabam limitando a significância dos resultados referentes ao todo. Levando-se em conta a tipologia da inovação apresentada por Hjalager (2010) no contexto analisado, as inovações de produto ou serviço e as de marketing foram mais comumente identificadas.

Algumas limitações da pesquisa - nomeadamente a concentração espacial, o número relativamente reduzido de empresas investigadas e a avaliação focada em apenas uma dimensão do radar - restringiram as possibilidades de fazer maiores generalizações e confirmar ou refutar discussões teóricas no tocante à realidade do turismo e, mais precisamente, do segmento de agências de turismo, mesmo em nível regional. Sugere-se, pois, o desenvolvimento de novas pesquisas com amostras mais expressivas abrangendo outras cidades, estados e regiões do país, que abordem avaliações focadas em outros segmentos da cadeia turística e em todas as dimensões da ferramenta RI.

Comparar os resultados de estudos obtidos em distintas áreas do território nacional, identificando as similaridades e diferenças nos processos de inovação, e pesquisar o impacto e a influência que as ações de inovação de determinada dimensão do radar exercem sobre outras e como elas podem variar de setor para setor constituem encaminhamentos para pesquisas futuras, que contribuirão para maior compreensão da realidade e de tendências do setor e, por conseguinte, para a elaboração de políticas e estratégias de âmbito público ou privado que solucionem ou amenizem o efeito de possíveis problemas identificados.

Finalmente, constatou-se que a aplicação do Radar da Inovação está condicionada a concepção, apreciação e interpretação do entrevistado, de tal sorte que a subjetividade envolvida nesse processo de avaliação pode comprometer ou distorcer a realidade. Ademais, foi mostrado que a ferramenta apresenta algumas limitações e questionamentos que precisam ser mais bem adaptados à realidade do segmento empresarial estudado e de outros que compõem a cadeia de turismo (hotéis, locadoras de veículos, bares e restaurantes e lazer e entretenimento, entre outros), já que estes possuem complexidades diversas entre si, que devem ser consideradas. A própria escala e classificação dos escores (apenas 1, 2 e 3) usada no RI é confusa. Nesse sentido, sugere-se que para cada grau de 1 a 5 fosse atribuída uma situação e, dessa forma, além de enriquecer a classificação, seria reduzida ou eliminada a probabilidade de invalidar o impacto de algumas ações de inovação implementadas pelas empresas diagnosticadas.

Destarte, o apontamento de indicadores comportamentais dessas empresas no tocante à inovação seria um ponto de partida interessante para criação e/ ou redefinição de instrumentos de medida da inovação mais apropriados para o setor. Isso facilitaria até mesmo a avaliação de instrumentos de medição como o RI que, diga-se de passagem, são escassos. A realização de pesquisas que contemplem essas questões é, pois, recomendada. 


\section{REFERÊNCIAS}

AGÊNCIA Sebrae de Notícias. (2013). Agências de viagens têm seu grau de competitividade avançado. Revista PEGN. Recuperado de: https://glo.bo/2jmlWp6

BACHMANN, D. L., \& Destefani, J. H. (2008). Metodologia para estimar o grau de inovação nas MPE. Curitiba, PR: Sebrae.

BAUTZER, D. (2009). Inovação: repensando as organizações. São Paulo, SP: Atlas.

BES, F. T., \& Kotler, P. (2011). A Bíblia da inovação: princípios fundamentais para levar a cultura da inovação contínua às organizações. São Paulo, SP: Lua de Papel.

BITTAR, A. A. M., Siqueira, D. P., Luz, L. C., \& Chacon, A. S. (2014). A dificuldade de pavimentar o caminho para a inovação tecnológica no Brasil: o retrato dos rankings, alguns indicadores e obstáculos à sua sustentabilidade. Cadernos de Prospecção, 7(4), 472-482. doi: 10.9771/S. CPROSP.2014.007.048

BRANDÃO, F., \& Costa, C. (2014). Inovação em turismo: uma abordagem sistémica e territorial. In C. Costa, F. Brandão, R. Costa \& Z. Breda (Eds.), Produtos e competitividade do turismo na lusofonia (pp. 70-89). Aveiro, Portugal: Escolar.

BRASIL. Subchefia para Assuntos Jurídicos da Casa Civil. (2008). Lei no 11.771, de 17 de setembro de 2008. Dispõe sobre a Política Nacional de Turismo, define as atribuições do Governo Federal no planejamento, desenvolvimento e estímulo ao setor turístico; revoga a Lei no 6.505, de 13 de dezembro de 1977, o Decreto-Lei no 2.294, de 21 de novembro de 1986, e dispositivos da Lei no 8.181, de 28 de março de 1991; e dá outras providências. Diário Oficial da União. Brasília, DF. Recuperado de: https://bit.ly/1jLGbtu

BRASIL. Subchefia para Assuntos Jurídicos da Casa Civil. (2014). Lei no 12.974, de 15 de maio de 2014. Dispõe sobre as atividades das Agências de Turismo. Diário Oficial da União. Brasília, DF. Recuperado de: https://bit.ly/2JLoM20

CAMISÓN, C., \& Monfort-Mir, V. M. (2012). Measuring innovation in tourism from the Schumpeterian and the dynamic-capabilities perspectives. Tourism Management, 33(4), 776-789. doi: 10.1016/j.tourman.2011.08.012.

CARVALHO, G. D. G., Silva, W. V., Póvoa, A. C. S., \& Carvalho, H. G. (2015). Radar da inovação como ferramenta para $o$ alcance de vantagem competitiva para micro e pequenas empresas. Revista de Administração e Inovação, 12(4), 162-186. doi: 10.11606/rai.v12i4.101898

CAVALCANTI, A. M., Cavalcanti Filho, A. M., \& Oliveira, M. R. G. (2012). Análise do desempenho em inovação das micro e pequenas empresas de TIC em Pernambuco. Revista Brasileira de Administração Científica, 3(2), 41-56. doi: 10.6008/ESS2179-684X.2012.002.0003

COSTA, H. A., \& Hoffmann, V. E. (2014). A cooperação entre micro e pequenas empresas (MPE) aglomeradas como recurso estratégico em destinos turísticos. In C. Costa, F. Brandão, R. Costa, \& Z. Breda (Eds.), Produtos e competitividade do turismo na Lusofonia (pp. 39-50). Aveiro, Portugal: Escolar.

FAYET, E. A. (2010). Inovação: conceitos e teorias. In: E. A. Fayet (Org.), Gerenciar a inovação: um desafio para as empresas. Curitiba, PR: IEL.

GOMEZELJ, D. O. (2016). A systematic review of research on innovation in hospitality and tourism. International Journal of Contemporary Hospitality Management, 28(3), 516-558. doi: 10.1108/IJCHM-10-2014-0510

HAUSER, J., Tellis, G. J., \& Griffin, A. (2006). Research on innovation: a review and agenda for marketing science. Marketing Science, 25(6), 687-717.

HJALAGER, A. M. (2010). A review of innovation research in tourism. Tourism Management, $31,1-12$.

KETOKIVI, M., \& Ali-Yrkkö, J. (2010). Innovation does not equal R\&D: strategic innovation profiles and firm growth. ETLA Discussion Paper, 1220. 
MACHADO, D. P. N., Dreher, M. T., \& Gorni, P. M. (2009). Inovação em serviços turísticos: a percepção desse processo em agências de viagens. Observatório de Inovação do Turismo, 4(1), 1-14. doi: 10.12660/oit.v4n1.5735.

MATTAR, F. (2005). Pesquisa de marketing. São Paulo, SP: Atlas.

OLIVEIRA, M. R. G., Cavalcanti, A. M., \& Paiva Junior, F. G. (2013). Mensurando a inovação por meio do grau de inovação setorial e do característico setorial de inovação. In Anais, Simpósio de Administração da Produção, Logística e Operações Internacionais, 2013, São Paulo, SP. São Paulo, SP: FGV.

ORGANIZAÇÃO para a Cooperação e Desenvolvimento Econômico. (2005). Manual de Oslo (3a ed.). São Paulo, SP: Finep.

PETERS, M., \& Pikkemaat, B. (2006). Innovation in tourism. Journal of Quality Assurance in Hospitality \& Tourism, 6(1), 1-6.

PINTO, H., \& Cruz, A. R. (2011). Sistemas de inovação e de turismo: complementaridades na região do Algarve. Revista Turismo \& Desenvolvimento, 15, 11-26. Recuperado de: https://bit.ly/2I8rG3W

SALVADO, J. O. M. G. (2009). Agências de viagens do futuro: um arquétipo para Portugal. Dissertação de Mestrado, Universidade de Aveiro, Aveiro.

SAWHNEY, M., Wolcott, R. C., \& Arroniz, I. (2006). The 12 different ways for companies to innovate. MIT Sloan Management Review, 47(3), 75-81. Recuperado de: https://bit.ly/ LWXVvR

SEBRAE-PR. (2017). Projeto Agentes Locais de Inovação. Pr.Sebrae.com.br. Recuperado de: http://app.pr.sebrae.com.br/ali/

SUNDBO, J., Orfila-Sintes, F., \& Sorensen, F. (2007). The innovatine behaviour of tourism firms: comparative studies of Denmark and Spain. Research Policy, 36(1), 88-106. doi: 10.1016/j.respol.2006.08.004

WEIDENFELD, A., Williams, A., \& Butler, R. (2010). Knowledge transfer and innovation among attractions. Annals of Tourism Research, 37(3), 604-626. Recuperado de: https:// bit.ly/2HOSToV

\section{AGRADECIMENTOS}

Esta pesquisa aborda parte da temática central da tese de doutorado da autora a saber, a medição da inovação em MPE de turismo -, de modo que são dignos de agradecimento o apoio e as valiosas contribuições dadas pelos professores Dr. Carlos Costa e Dra. Filipa Brandão, da Universidade de Aveiro, pelos avaliadores / revisores da revista Turismo em Análise da Universidade de São Paulo (USP) e pelas instituições Coordenação de Aperfeiçoamento de Pessoal de Nível Superior (Capes), CNPq e Sebrae.

\section{CONTRIBUIÇõES}

Autoria única. 